\title{
An Assessment of Curriculum For Behaviour Change Among Learners With Emotional And Behaviour Disorders In Selected Juvenile Schools In Kenya
}

\author{
James Muthomi Rintaugu \\ Kenyatta University, Kenya
}

\begin{abstract}
In a global, regional and Kenyan perspective, there is a challenge as to the best curriculum to use for behaviour change among learners with Emotional and Behaviour Disorders (EBD). This study assessed curriculum for behaviour change among learners with EBD in selected Juvenile Schools (JS) in Kenya. The study was based on the social learning theory. Cross sectional descriptive research design was used. Target population comprised of all the learners in the selected JS and their managers in selected JS in Kenya. There was a total of 646 respondents. Probabilistic sampling techniques were used to select the sample. Questionnaires, interview schedules, focus group discussion, document analysis and observation schedules were used for data collection. Quantitative and qualitative data was collected, analyzed and presented. The study found that the adapted curriculum for learners with EBD was missing in JS despite being referral institutions for behaviour change. Similarly, the curriculum did not address problem solving and coping skills. The study recommends adaptation of the curriculum to address behaviour change.
\end{abstract}

Keywords: Curriculum, Adapted, Juvenile Schools, Special Needs Education.

\section{BACKGROUND}

$\mathrm{I}$ n a global view, Kauffman and Polloway (2017), in a study on demographic trends in educational programs for students with EBD in USA, established that learners with EBD have significant difficulties in adjusting to school environment. As a result, educators are challenged on how best to provide for their educational needs.

In Germany, about $10 \%$ of children and about $18 \%$ of adolescents are considered to have EBD related challenges (Clinic for Child Psychosomatics, 2005). Learners in this context are remedied through early interventions and specialized interpretations of their problems.

Das and Shah (2014), in their study on Special Education today in India, points out that learners with EBD are mainly educationally deprived due to social-economic reasons and curriculum not addressing learner's needs.

In Kenya, EBD is the least supported category of learners with disabilities with only $2 \%$ support (Kenya Institute of Special Education (KISE, 2017)). Thus, the question of behaviour change support through the appropriate curriculum is at stake.

In a case study in Nakuru County on effects of armed ethnic conflict on education of children and the implication for peace education, (Ngundo, 2013), argues: that behaviour change in children and adults occurs over time and in an environment which favours the change. That is, by the use of a curriculum addressing behavioral needs of learners with EBD.

Article 54 of the Constitution of Kenya (2010), stipulates that Persons with disabilities (PWDs) are entitled to access educational institutions and facilities especially those that are integrated into society to the extent compatible with their interests. However, learners with EBD are incarcerated in JS under a curriculum which does not address behaviour change as established in Ndaita, 2017's study on psychosocial factors influencing juvenile delinquency among girls at Kirigiti and Dagorretti rehabilitation schools in Nairobi, Kenya. The children's act (2001), stipulates that researchers and professionals handling children with disabilities should continuously find the best strategies to address their special needs. Article 18 of Persons with disabilities act (2013), guides learning institutions to take into account the special needs of persons with disabilities with respect to the curriculum.

Therefore, to address these challenges on behaviour change among learners with EBD, curriculum for behaviour change formed the key focus of this study.

\section{CURRICULUM FOR BEHAVIOUR CHANGE}

Hanover's (2013), study on effective programs for EBD established that curriculum for learners with EBD ought to be precisely adapted to cater for the special learning needs of each individual. In her study, she used only questionnaire but in this study, questionnaires, interview guide to the managers and document analysis were used to seek the curriculum for behaviour change in the selected JS.

Phoenix Curriculum (2018), in a study on comprehensive resources to combat gang involvement and other delinquencies, established that there were above $50 \%$ rates of reported recidivism in New Jersey State. An observation attributed to non-use of problem solving and coping skills in teaching learners with EBD. For the learners with EBD who were taught using problem solving and coping skills, only $10 \%$ of recidivism was reported. However, Phoenix Curriculum (2018), didn't establish duration for implementing problem solving and coping skills. The current study sought 
the existence of problem solving and coping skills, duration taught and their tasks analysis in JS.

In Kenya, the Ministry of Education (2009), guides that curriculum should entail organized experiences that schools offer to help learners learn and develop. This guide expounds on the subjects taught, the content, the school environment and other organized learning enrichment activities that take place in and outside the classroom. However, a guide on a curriculum for behaviour change among learners with EBD is missing. It is this missing link for a curriculum for learners with EBD in JS that this study sought to address.

Wambugu (2014), in a study on examination of special needs education aspects embedded in juvenile rehabilitation programmes in Kenya and the resultant rehabilitation outcomes, revealed that JS did not have specific curriculum for behaviour change and each institution designs its own. In this case then standardization becomes elusive and it is not clear how each address itself to aspects to do with behaviour change. It is on this basis that this study sought to establish the nature of curriculum used in the selected JS. Further, Ngundo (2013), in a study on effects of armed ethnic conflict on education of children and the implication for peace education, a case study of Nakuru County, Kenya found that curriculum for teaching learners with behavioural problems about peaceful coexistence cannot be implemented without proper structures in place. Ngundo (2013), recommends positive behaviour change and coping mechanisms to be integrated in academic subjects.

In a study on referral mechanisms for restorative justice in Tanzania, Kilekamajenga (2018), found that intrusive security measures in schools diminishes the rights of students and increases the likelihood of misconduct. Similarly, Ndaita (2017), in a study on psychosocial factors influencing juvenile delinquency among girls at Kirigiti and Dagorretti rehabilitation Centres in Nairobi, Kenya found that community (issues such as alcoholism and peer pressure) greatly affect learners with EBD in and out of rehabilitation Schools. Kilekamajenga (2018), and Ndaita (2017), recommend child friendly environment and non-rigid approaches. The researcher sought for presence of curriculum with child friendly environment and non-rigid approaches in JS of selected Counties in Kenya. That is, positive behaviour change environment.

On educational resources and corrective education practices, Ergetachew (2016), in a study on teaching policies and learning outcomes in Sub-Saharan Africa, issues and options, established that in spite of huge transformations in sub-Sahara Africa, educational progress has not been met with meaningful improvements in educational resources and corrective education practices. Many schools in Sub-Sahara Africa are overcrowded and under resourced, lacking basic classroom resources. The current study examined the presence and use of corrective education resources for learners with EBD in selected JS.
In Kenya, a research on National survey on children with disabilities and special needs in education by KISE (2017), revealed that there is inappropriate infrastructure, inadequate facilities, supervision and monitoring for learners with special needs included in regular institutions. The inadequacy has a direct bearing on quality of education as it hinders effective curriculum implementation. Hence, causes of inadequacies in terms of curriculum for behaviour change were sought.

\section{METHODOLOGY}

The study adopted a cross sectional descriptive research design, to capture the dynamics of curriculum for behaviour change in JS.

\section{Locale of the study}

The study was carried out in selected JS in Kenya. They were in three administrative counties namely Nairobi, Kiambu and Kirinyaga. Selection was due to high population of learners and their heterogeneity (in terms of their backgrounds) and gender parity.

\section{FINDINGS ON CURRICULUM FOR LEARNERS WITH EBD IN JUVENILE SCHOOLS}

To establish the curriculum used for behaviour change among learners with EBD, the study sought; the academic subjects taught, school environment, educational resources and corrective educational practices in the selected JS. Interview and documentary analysis were the data sources for this objective.

\subsection{Academic Subjects}

The study sought to find out whether problem solving and coping skills were taught in the JS. As per the curriculum used in Kenyan JS, the subjects were analyzed in two categories which are problem solving and coping skills. This was by analyzing the existing curriculum guides, schemes of work and carrying out interviews with managers. The results are shown in Figure 4.1.

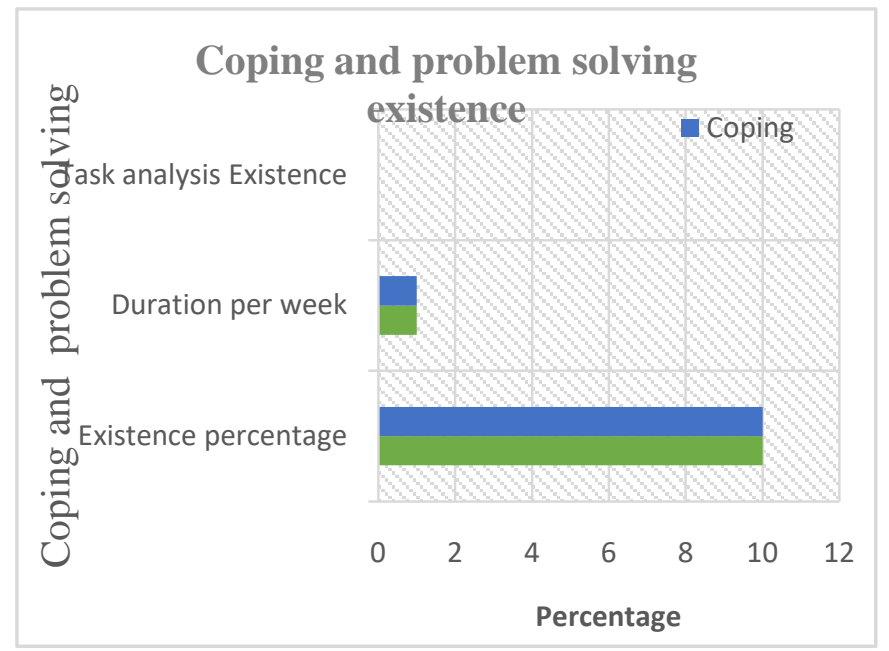

Figure 4.1. Behaviour change skills (problem solving and coping skills) 
From Figure 4.1, the existence of problem solving and coping skills in the academic subjects being taught in JS was at $10 \%$. This low percentage is interpreted as being insignificant. The duration per week of study in which the skills were practiced was $5 \%$. It was also interpreted to be insignificant. For the evidence of task analysis incorporating problem solving and coping skills, was practiced at $0 \%$. Thus, it was literally missing in JS as a tool for behaviour change. Thus, from this finding, problem solving and coping skills were unnoticeable in the academic subjects taught to learners with EBD in the JS. Yet these schools use education as an element for behaviour change. Thus, this result is a precursor for recidivism as observed by Phoenix Curriculum (2018), in their study on comprehensive resources to combat misbehaviours. Thus, from academic subjects being taught, problem solving and coping skills existence was very negligible. Thus, likely to leading to shortfalls in behaviour change among the learner with EBD.

\subsubsection{School environment}

For school environment, which was a subheading under the objective on curriculum, data was established by use of interviews for the school managers, questionnaires for learners in JS, document analysis and observation schedules for learners with EBD in JS during outdoor activities. The findings were reported in terms of intrusive, rigid and barrier free environment influences on behaviour change. The findings are visually presented as shown in Figure 4.2.

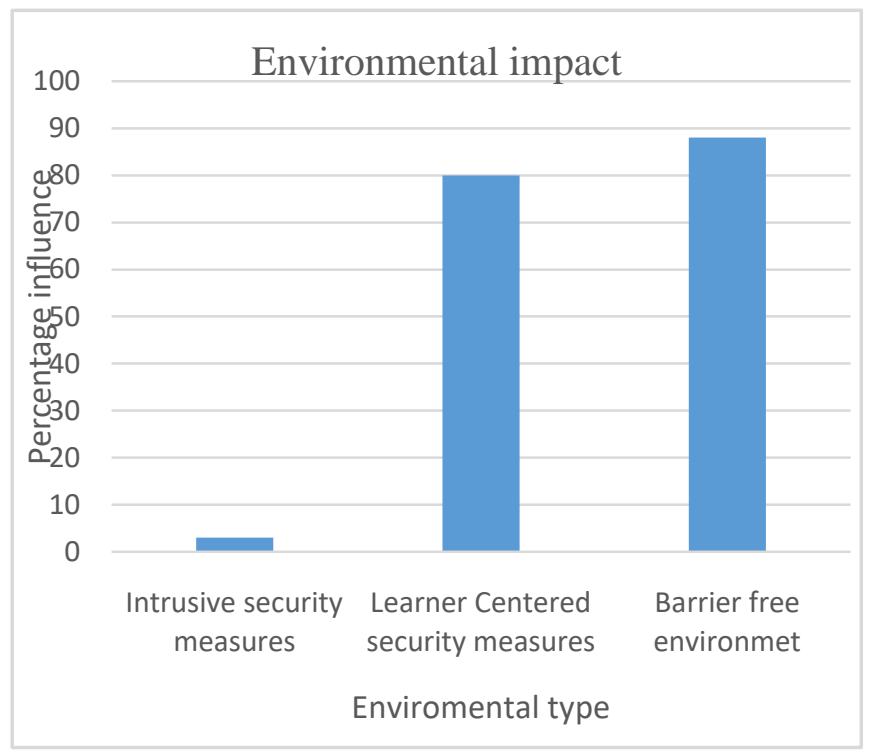

Figure 4.2 Environmental influences on behaviour change

From Figure 4.2, barrier free environment recorded the highest percentage $(88 \%)$ in positively influencing behaviour change. Learner centered security measures had an $80 \%$ on positive behaviour change influence while intrusive measures recorded the lowest (3\%) in terms of positive behaviour change influence. However, from qualitative data obtained, it was established that in the Kenyan JS, intrusive measures existed at an $80 \%$ rating in the selected JS despite their low influence (3\%) in positive behaviour change. Learner centered approaches existed at a $40 \%$ rating despite their recorded $80 \%$ effect of positive behaviour change. Barrier free environment recorded $35 \%$ despite having an $88 \%$ influence on positive behaviour change. The above findings agree with the National Association of School Psychologists (2018), who argues that rigid and intrusive measures in schools diminishes the rights of learners and increases misconduct. Also, Adrienne and Fernandes (2018), in their study on the background of vulnerable youth and juvenile school policies, observed that environment can either increase or decrease prevalence of misbehavior. However, this study has established that even though barrier free environment recorded the highest (88\%) in terms of positive behaviour influence, in Kenya's JS, it was not practiced. Similarly, learner centered approach was not practiced in the selected JS. That the learners had very minimal interactions with the schools (regular and nonregular) neighboring the JS, religious centres among other institutions in their immediate environment owing to the confinement regulations. A finding which is not in line with Ngundo's (2013), argument that behaviour change in children and adults occurs over time and in an environment (barrier free, learner centered approaches and less intrusive) which favours the change.

\subsubsection{Educational resources and corrective educational practices}

On the aspect of educational resources and corrective educational practices, investigations were done through interviews to managers, document analysis, questionnaires administered to the learners and the observation schedules. The outcome is as shown in Figure 4.3.

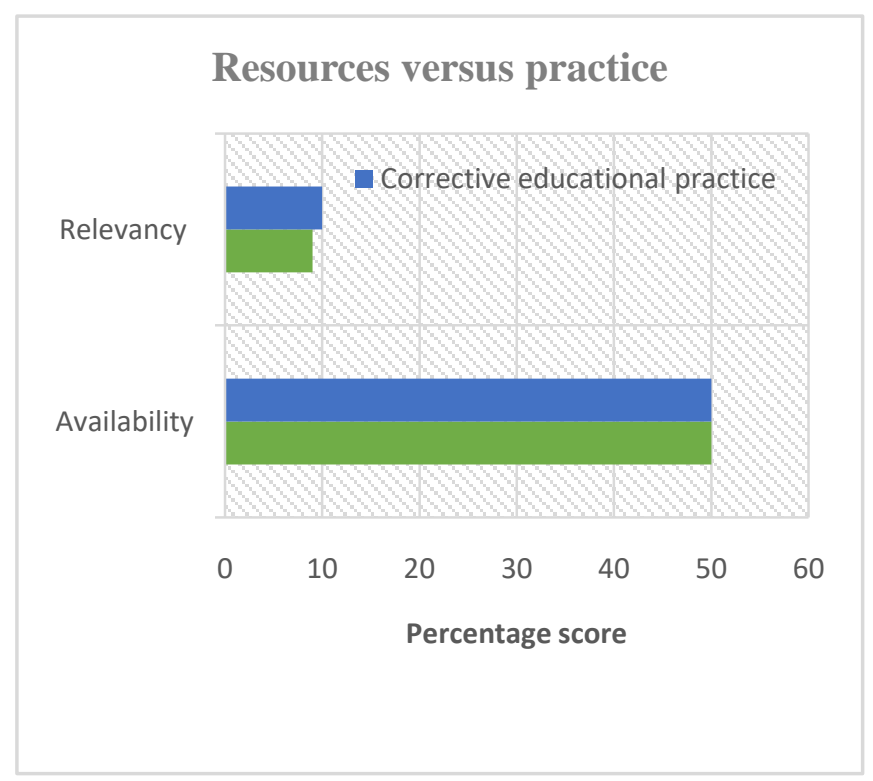

Figure 4.3. Educational Resources and corrective practices

From Figure 4.3, availability of educational resources and corrective educational practices were found to be at $50 \%$, interpreted by the researcher to mean average level. Educational resources in this study included; presence of 
textbooks, basic instructional materials, desks, and chairs. Corrective educational practices included; supervision, monitoring and evaluation strategies. This finding of average score concurs with Ergetachew (2016), work on teaching policies and learning outcomes, that in sub-Sahara Africa, educational resources and corrective education practices are yet to be met. Hence, without learning outcomes being met, behaviour change was unlikely to happen.

In terms of relevancy to learners with EBD, educational resources and corrective educational practices, recorded a $9 \%$ and $10 \%$ respectively. This in essence means that they are not relevant for learners with EBD. The low score was attributed to non adaptiveness of the existing resources and practices to special needs of the learners. This finding is in congruence with Kenya Institute of Special Education (2017), argument that inappropriate infrastructure, inadequate facilities, lack of assistive devices and equipment for learners with special needs and disability are rampant in many schools in the Kenya.

These findings mean that the curriculum for learners with EBD in JS, that is subjects taught, the content, the school environment and all other organized learning enrichments affect the learners with EBD in the process of behaviour change. It essentially means that the JS did not use an adaptive curriculum to address the needs of learners with EBD. The regular school curriculum (for learners without special needs) was followed despit that JS were referral institutions for behaviour change. And that curriculum for behaviour change ought to be in place in JS.

\section{SUMMARY OF KEY FINDINGS}

The study observed that the selected JS were not using a specialized curriculum for learners with EBD. The curriculum used did not adequately deal with the problem solving and coping skills. These skills are significantly useful in helping learners with EBD to undergo positive behaviour change.

In terms of whether the school environment provided an intrusive, rigid or barrier free environment influence on behaviour change, the study shows that the school environment has more rigid and intrusive measures as opposed to being flexible and child friendly.

The educational resources and corrective educational practices were fairly available. In terms of their relevancy, they were mostly non adaptiveness to suit the special needs of learners with EBD in JS. Thus, inappropriate infrastructure and inadequate facilities was rampant. For the infrastructure and facilities, they were either outdated or non-functional.

\section{CONCLUSION}

The main purpose of this study was to assess curriculum for behaviour change among learners with EBD in selected JS in Kenya. On this basis, the following was concluded:
1. That the curriculum used in the selected JS was not adapted to the needs of learners with EBD.

2. That the school environment was rigid and intrusive as opposed to being flexible and learner friendly.

\section{RECOMMENDATION}

That the Ministry of Education, Ministry of labour and social protection, Kenya Institute for curriculum development (KICD) and Kenya Institute of Special Education (KISE) should collaborate in developing an adapted curriculum for learners with EBD in JS.

\section{REFERENCES}

[1] Adrienne L. \& Fernandes. (2018). vulnerable youth: background and policies. Congressional Research Service. Retrieved from www.crs.gov;RL33975

[2] Constitution of Kenya. (2010). Republic of Kenya, Government Press.

[3] Das, A \& Shah, R. (2014). Special Education today in India. Special Education International Perspectives: Practices across the Globe Advances in Special Education.

[4] Ergetachew, D. (2016). Teaching policies and learning outcomes in Sub-Saharan Africa Issues and Options. United Nations Educational, Scientific and Cultural Organization (UNESCO)International Institute for Capacity Building in Africa (IICBA).

[5] Hanover.(2013). Effective programs for emotional and behavioral disorders. Germany; District Administration Practice.

[6] Kauffman, M. \& Polloway, E. (2017). Demographic Trends in Educational Programs for Students with Emotional and Behavioral Disorders. University of Lynchburg; VA 24501434544-8655.

[7] Kenya Institute of Special Education. (2017). National survey on children with disabilities and special needs in education. Nairobi Kenya.

[8] Kilekamajenga, N., (2018). Referral mechanisms for restorative justice in Tanzania. Retrieved from: http://dx.doi.org/10.17159/2413-3108/2018/v0n63a4368T

[9] Ministry of Education. (2009). The national special needs education policy framework. Republic of Kenya, Government Press.

[10] National Association of School Psychologists. (2018). School security measures and their impact on students. USA; Bethesda Soft works.

[11] Ndaita, T. (2017). Psychosocial factors influencing juvenile delinquency among girls at Kirigiti and Dagorretti rehabilitation Centres in Nairobi, Kenya. University of Nairobi; unpublished master's thesis.

[12] Ngundo, L., W. (2013). Effects of armed ethnic conflict on education of children and the implication for peace education, a case study of Nakuru County, Kenya. Retrieved from: https://irlibrary.ku.ac.ke/handle/123456789/9076?show=full

[13] Persons with disabilities act (2013). Kenya; National Council for Law Reporting.

[14] Phoenix Curriculum. (2018). Comprehensive resources to combat gang involvement and other delinquencies. USA; New Jersey; Phoenix Resources. Retrieved from www.phoenixcurriculum.com

[15] Wambugu, B., N. (2014). An examination of special needs education aspects embedded in juvenile rehabilitation programmes in kenya and the resultant rehabilitation outcomes. Retrieved

from https://pdfs.semanticscholar.org/9667/f680f5151213373bfbdd5a1d 2199cfd083c7.pdf 